\title{
Association of Glycemic Control Trajectory with Short-Term Mortality in Diabetes Patients with High Cardiovascular Risk: a Joint Latent Class Modeling Study
}

\author{
Sridharan Raghavan, MD, $P h D^{1,2,3,4}$, Wenhui G. Liu, MS ${ }^{7}$, Seth A. Berkowitz, MD ${ }^{5}$, \\ Anna E. Barón, PhD ${ }^{7,6}$, Mary E. Plomondon, $P h D^{7}$, Thomas M. Maddox, $\mathrm{MD}^{7}$, \\ Jane E.B. Reusch, MD ${ }^{7,8}$, P. Michael Ho, MD, PhD ${ }^{7,9}$, and Liron Caplan, MD, PhD 1,10
}

\begin{abstract}
'Department of Veterans Affairs, Eastern Colorado Healthcare System, Aurora, CO, USA; ${ }^{2}$ Division of Hospital Medicine, Department of Medicine, University of Colorado School of Medicine, Aurora, CO, USA; ${ }^{3}$ Colorado Cardiovascular Outcomes Research Consortium, Aurora, CO, USA; ${ }^{4}$ Rocky Mountain Regional VA Medical Center Medicine Service (1 1 1), 1700 North Wheeling Street, Aurora, CO, USA; ${ }^{5}$ Division of General Medicine \& Clinical Epidemiology, University of North Carolina School of Medicine, Chapel Hill, NC, USA; 6 Department of Biostatistics and Informatics, Colorado School of Public Health, Aurora, CO, USA; ${ }^{7}$ Division of Cardiology, Washington University School of Medicine, St. Louis, MO, USA; ${ }^{8}$ Division of Endocrinology, Metabolism, and Diabetes, University of Colorado School of Medicine, Aurora, CO, USA; ${ }^{9}$ Division of Cardiology, University of Colorado School of Medicine, Aurora, CO, USA; ${ }^{10}$ Division of Rheumatology, University of Colorado School of Medicine, Aurora, CO, USA.
\end{abstract}

BACKGROUND: The relationship between risk factor or biomarker trajectories and contemporaneous short-term clinical outcomes is poorly understood. In diabetes patients, it is unknown whether hemoglobin Alc (HbAlc) trajectories are associated with clinical outcomes and can inform care in scenarios in which a single HbAlc is uninformative, for example, after a diagnosis of coronary artery disease (CAD).

OBJECTIVE: To compare associations of HbAlc trajectories and single $\mathrm{HbAlc}$ values with short-term mortality in diabetes patients evaluated for $\mathrm{CAD}$

DESIGN: Retrospective observational cohort study

PARTICIPANTS: Diabetes patients $(n=7780)$ with and without angiographically defined CAD

MAIN MEASURES: We used joint latent class mixed models to simultaneously fit HbAlc trajectories and estimate association with 2-year mortality after cardiac catheterization, adjusting for clinical and demographic covariates.

KEY RESULTS: Three HBAlc trajectory classes were identified: individuals with stable glycemia (class A; $n=$ 6934 [89\%]; mean baseline HbAlc 6.9\%), with declining HbAlc (class B; $n=364$ [4.7\%]; mean baseline HbAlc $11.6 \%$ ), and with increasing HbAlc (class C; $n=482$ [6.2\%]; mean baseline HbAlc 8.5\%). HbAlc trajectory class was associated with adjusted 2 -year mortality (3.0\% [95\% CI 2.8, 3.2] for class A, 3.1\% [2.1, 4.2] for class $\mathrm{B}$, and $4.2 \%[3.4,4.9]$ for class $\mathrm{C}$; global $P=0.047, P=$ 0.03 comparing classes $\mathrm{A}$ and $\mathrm{C}, \mathrm{P}>0.05$ for other pairwise comparisons). Baseline $\mathrm{HbAlc}$ was not associated with 2-year mortality $(P=0.85$; hazard ratios 1.01 $[0.96,1.06]$ and $1.02[0.95,1.10]$ for HbAlc $7-9 \%$ and $\geq$ $9 \%$, respectively, relative to $\mathrm{HbAlc}<7 \%)$. The association

Electronic supplementary material The online version of this article (https://doi.org/10.1007/s11606-020-05848-5) contains supplementary material, which is available to authorized users.

Received September 3, 2019

Revised February 29, 2020

Accepted April 8, 2020

Published online April 24, 2020 between HbAlc trajectories and mortality did not differ between those with and without CAD (interaction $P=0.1$ ). CONCLUSIONS: In clinical settings where single HbAlc measurements provide limited information, HbAlc trajectories may help stratify risk of complications in diabetes patients. Joint latent class modeling provides a generalizable approach to examining relationships between biomarker trajectories and clinical outcomes in the era of near-universal adoption of electronic health records.

KEY WORDS: diabetes; hemoglobin Alc trajectory; cardiovascular disease; mortality.

J Gen Intern Med 35(8):2266-73

DOI: $10.1007 / \mathrm{s} 11606-020-05848-5$

(c) Society of General Internal Medicine 2020

\section{INTRODUCTION}

In the era of electronic health records (EHR), repeated measurements of biomarkers and disease risk factors are readily available, but most clinical guidelines recommend treatment decision-making based on solitary measurements. While guidelines for common chronic diseases such as diabetes and hypertension base recommendations on the last available value, ${ }^{1,2}$ there may be clinical scenarios in which the last available measurement is a poor predictor of clinical outcomes. In such scenarios, the integration of serial biomarker measurements into trajectories may be clinically informative. That is, the biomarker trajectory may reflect risk of an important clinical outcome, irrespective of a causal mechanism. However, the relationship between risk factor or biomarker trajectories and clinical outcomes remains poorly understood.

Diabetes mellitus, a disease in which a biomarkerhemoglobin A1c (HbA1c)-is measured serially to monitor glycemic control, provides a model clinical context in which to evaluate differential associations of a single $\mathrm{HbA} 1 \mathrm{c}$ value and longitudinal trajectories with clinical outcomes. HbAlc is 
a predictor of diabetes complications and mortality, ${ }^{1,3-10}$ and professional society guidelines recommend serial $\mathrm{HbA} 1 \mathrm{c}$ monitoring. However, the guidelines do not offer diabetes management recommendations based on $\mathrm{HbA} 1 \mathrm{c}$ trajectory.

11 Thus, clinical providers typically adjust diabetes treatment based on the last available HbA1c measurement, even though that single value does not predict meaningful clinical outcomes in certain clinical settings.

One clinical scenario in which the last available HbAlc measurement is not associated with short-term clinical outcomes occurs after myocardial infarction (MI) or percutaneous coronary intervention (PCI) for coronary artery disease (CAD). ${ }^{12-15}$ In this study, we used a realworld cohort of diabetes patients undergoing diagnostic evaluation for CAD to identify glycemic control trajectories, describe the characteristics of patients with distinct $\mathrm{HbAlc}$ trajectories, and compare the associations of $\mathrm{HbAlc}$ trajectories and single $\mathrm{HbA} 1 \mathrm{c}$ measurements with short-term mortality.

\section{METHODS}

\section{Study Cohort}

We included all US veterans diagnosed with diabetes prior to October 2015 who underwent coronary angiography for indications related to $\mathrm{CAD}$ in the US Veterans Affairs (VA) healthcare system between October 2005 and September 2016. Data were recorded in a standardized fashion through the VA Clinical Assessment, Reporting, and Tracking Program (CART). ${ }^{16}$ We identified diabetes patients as those with at least one ICD-9 diabetes diagnosis code for inpatient encounters or at least two ICD-9 diabetes codes for outpatient visits on separate days, excluding codes for secondary diagnosis of diabetes. ${ }^{17}$ To avoid confounding by diabetes duration, we included individuals who met the diabetes definition within 24 months of their index cardiac catheterization and excluded those who had a qualifying diabetes diagnosis code more than 2 years prior to catheterization or were newly diagnosed with diabetes at the time of catheterization. To be included, participants had to have at least 6 months of records in the VA preceding index catheterization, at least one HbAlc measurement in the 24 months preceding angiography, and at least one HbA1c measurement during follow-up. We included individuals whose indication for angiography was related to CAD (chest pain, stable angina, positive functional study, or ischemic heart disease). For patients with multiple angiographies, we used HbAlc values after their first cardiac catheterization for this study and excluded patients with a prior MI or coronary revascularization. Loss to follow-up was defined as those with fewer than 3 months of follow-up time (without an outcome event) after catheterization.
The Colorado Multiple Institution Review Board provided human subjects oversight and approval.

\section{Exposures, Outcomes, and Covariates}

The primary exposure was HbA1c trajectory during follow-up after cardiac catheterization, using the last HbA1c measurement before catheterization and all $\mathrm{HbA} 1 \mathrm{c}$ measurements up to 2 years after catheterization. The primary outcome was 2year all-cause mortality measured using VA vital status data. All multivariable models were adjusted for demographics (age, sex, race), cardiovascular risk factors (hypertension, hyperlipidemia, Framingham risk score, smoking status, body mass index), comorbidities (heart failure [HF], chronic obstructive pulmonary disease, post-traumatic stress disorder, peripheral artery disease, chronic kidney disease, dialysis, depression), post-angiography revascularization (none, PCI, coronary artery bypass graft), diabetes duration, and medication adherence at baseline for cardioprotective medications (HMG-CoA reductase inhibitors [statins], angiotensinconverting enzyme inhibitors [ACEi] or angiotensin receptor blockers [ARB], and beta-blockers) based on proportion of days covered (PDC) dichotomized at a threshold of $\geq 0.8 .{ }^{18}$ In secondary analyses, we included CAD burden as a covariate and in an interaction term with HbAlc trajectory using standard definitions of flow-limiting stenosis ${ }^{19}$ (Online Supplement, Table S7). All variables included in multivariable models are described in the Online Supplement (Table S7).

\section{Statistical Analyses}

We opted to model HbA1c trajectories and associations with mortality jointly using joint latent class mixed models, ${ }^{20,21}$ overcoming limitations of the two-stage approach to trajectory analysis used in prior studies of diabetes patients, ${ }^{22-24}$ particularly that the two-stage study design precludes estimation of contemporaneous associations between trajectories and outcomes. ${ }^{25,26}$ Joint latent class modeling provides an alternative approach to trajectory analysis in which the risk factor trajectories and their associations with an outcome can be estimated contemporaneously. $^{20,21}$ The rationale for the study design is described in detail in the Online Supplement.

We performed the analyses in three steps. First, we fit a series of latent class trajectory models to determine the functional form of time and number of latent classes that best fit the data. $^{25,}{ }^{26}$ We used Bayes information criteria (BIC) as the primary measure of model fit, and secondarily assessed the mean posterior probability of class membership across classes. Models with a third-degree fixed effect for time, a seconddegree random time effect, and three latent $\mathrm{HbAlc}$ trajectory classes with an autoregressive covariance structure to account for correlation between repeated $\mathrm{HbA} 1 \mathrm{c}$ measurements best fit the data. Details of model selection are available in the Online Supplement. As a sensitivity analysis of the trajectory models, we verified that a three-trajectory model best fit the data after 
limiting the sample to individuals using at least one diabetes medication at baseline (Fig. S1).

The second step in the analysis was to compare patient-level demographics, cardiovascular risk factors, diabetes-related variables, and other covariates across HbAlc trajectory classes. We used chi-square tests for categorical data and KruskalWallis tests for continuous or ordinal data to compare variables across $\mathrm{HbAlc}$ trajectory classes. The third step in the analysis was to test associations between $\mathrm{HbAlc}$ trajectory classes and mortality using joint latent class mixed models ( $\mathrm{R}$ package lcmm). This approach jointly identifies subgroups of patients with different $\mathrm{HbAlc}$ trajectories after index catheterization and estimates associations with mortality contemporaneous$1 y .{ }^{20,21}$ For the joint latent class survival model, class-specific baseline mortality risk was modeled with a Weibull distribution, and the effects of covariates were assumed constant over time. Finally, we used an omnibus interaction test to assess whether $\mathrm{HbAlc}$ trajectory classes and their associations with mortality varied across levels of CAD burden. As a sensitivity analysis, we repeated the primary analyses in participants without $\mathrm{HF}$ at baseline.

We also performed an exploratory analysis comparing diabetes medication prescriptions and adherence across individuals in different $\mathrm{HbA} 1 \mathrm{c}$ trajectory classes. Based on prescription drug fills in the VA at baseline and 0-6, 6-12, and 1224 months after catheterization, individuals were classified as being prescribed metformin, sulfonylureas, insulin, or other diabetes medication classes. We compared the classes of diabetes medications prescribed and the number of distinct medication classes used for each individual during each of the time intervals. For adherence, we compared PDC (dichotomized at 0.8 ) for ACEi/ARB, beta-blockers, statins, sulfonylureas, and metformin at 12 months after cardiac catheterization among individuals who had survived for a year.

All analyses were performed in R (version 3.1, R Foundation for Statistical Computing, Vienna, Austria), and statistical code is available upon request.

\section{RESULTS}

We studied 7780 diabetes patients with a mean diabetes duration of 1.1 years at the time of cardiac catheterization. Of these, 7492 (96\%) were men, 6141 (79\%) were white, and their average age was 62 years. The majority of participants had obstructive $\mathrm{CAD}$ on the index catheterization $(62 \%)$, while $20 \%$ had non-obstructive CAD, and $18 \%$ had no CAD. Demographic, comorbidity, and treatment-related variables for the full study cohort are summarized in Table 1. Participants had a median of $2 \mathrm{HbA} 1 \mathrm{c}$ measurements in the first 6 months of follow-up and 5 over the 2-year follow-up period (Table S8).

Joint latent class mixed models with three $\mathrm{HbAlc}$ trajectory classes best fit the data: individuals with stable glycemia (class A, $n=6934,89 \%$ ), individuals with a decline in HbAlc after catheterization (class B, $n=364,4.7 \%$ ), and individuals with an increase in $\mathrm{HbAlc}$ after catheterization (class C, $n=482$, 6.2\%) (Fig. 1). Mean HbAlc at the time of catheterization was highest in class B (11.6\%), lowest in class A (6.9\%), and intermediate in class $\mathrm{C}(8.5 \%)$ (Table 1). By 6 months after cardiac catheterization, class $\mathrm{C}$ individuals had the highest predicted HbAlc in the trajectory model $(9.6 \%$ [95\% CI 9.3, 9.9] for class $\mathrm{C}, 8.8 \%$ [8.5, 9.1] for class $\mathrm{B}$, and 7.0\% [6.9, 7.1] for class A; Fig. 1). Compared to class B and class $\mathrm{C}$ individuals, those in class A were older on average, more likely to be white, less likely to have HF, had the highest Framingham cardiovascular risk score on average, and were more likely to be adherent to cardioprotective medications at baseline (Table 1).

Crude mortality rates across $\mathrm{HbA} 1 \mathrm{c}$ trajectory classes were $4.3 \%$ in class A, $4.7 \%$ in class B, and $5.0 \%$ in class C. Crude 2year mortality based on HbAlc values, as opposed to trajectory classes, was higher in individuals with $\mathrm{HbAlc} \geq 9 \%$ than in those with $\mathrm{HbAl} 1 \mathrm{c}<7 \%$ or 7-9\%, based on a single baseline measurement or based on the mean of all $\mathrm{HbAlc}$ measurements over 12 or 24 months of follow-up after cardiac catheterization (Table S9). In multivariable joint latent class mixed models, adjusted 2-year mortality differed across trajectory classes (adjusted mortality rate of $3.0 \%$ [95\% CI 2.8, 3.2] in class A, 3.1\% [95\% CI 2.1, 4.2] in class B, and 4.2\% [95\% CI 3.4, 4.9] in class $\mathrm{C} ; P=0.047$ for difference between classes; Fig. 2a). Adjusted mortality differed significantly between classes $\mathrm{A}$ and $\mathrm{C}(P=0.03)$ but not between classes $\mathrm{A}$ and $\mathrm{B}$ $(P=0.9)$ or between classes B and C $(P=0.5)$ (Fig. 2a). In identical multivariable Cox proportional hazard models, baseline $\mathrm{HbA} 1 \mathrm{c}$ was not associated with 2-year mortality (Table 2). The HbA1c trajectory classes observed were similar among participants without $\mathrm{HF}$ at baseline compared to the full study sample (Fig. S2). Among those without HF, the predicted survival probability curves diverged initially between classes $\mathrm{A}$ and $\mathrm{C}$ (adjusted 1-year mortality of $1.47 \%$ in class A vs $2.37 \%$ in class C) but came together at two years resulting in a non-significant association between trajectory class and 2-year mortality (Fig. S2, $P=0.95$ ).

The association between $\mathrm{HbAlc}$ trajectory class and mortality did not differ between those with no CAD, non-obstructive $\mathrm{CAD}$, and obstructive $\mathrm{CAD}$ (interaction $P=0.1$. Mortality events were less common among those with no CAD or non-obstructive CAD than in those with obstructive CAD such that the joint model results were driven by those with obstructive CAD. Among individuals with obstructive CAD, variation in baseline clinical characteristics across trajectory classes was similar to that observed for the full study population (Table S10), and mortality differed across trajectory classes in multivariable joint latent class mixed models (adjusted mortality rate of $3.8 \%$ [95\% CI 3.5, 4.1] in class $\mathrm{A}, 4.9 \%$ [95\% CI 3.6, 6.2] in class $\mathrm{B}$, and $6.1 \%$ [95\% CI 4.9, 7.2] in class C; $P=0.039$ for difference between classes; Fig. 2b). Mortality differed between 
Table 1 Characteristics of All Study Participants and Stratified by Hemoglobin A1c (HbA1c) Trajectory Class After Cardiac Catheterization

\begin{tabular}{|c|c|c|c|c|c|}
\hline & \multirow{3}{*}{$\begin{array}{l}\text { All participants } \\
n=7780\end{array}$} & \multicolumn{3}{|c|}{ Hemoglobin A1c trajectory class } & \multirow[t]{3}{*}{$P$ value } \\
\hline & & \multirow{2}{*}{$\begin{array}{l}\text { Class A } \\
n=6934\end{array}$} & \multirow{2}{*}{$\begin{array}{l}\text { Class B } \\
n=364\end{array}$} & \multirow{2}{*}{$\begin{array}{l}\text { Class C } \\
n=482\end{array}$} & \\
\hline & & & & & \\
\hline Age (years), mean (SD) & $61.9(8.3)$ & $62.3(8.2)$ & $58.4(8)$ & $58.1(8)$ & $<0.0001$ \\
\hline Male, $n(\%)$ & $7492(96.3)$ & $6683(96.4)$ & $347(95.3)$ & $462(95.9)$ & 0.51 \\
\hline \multicolumn{5}{|l|}{ Race, $n(\%)$} & $<0.0001$ \\
\hline White & $6141(78.9)$ & $5545(80)$ & $255(70.1)$ & $341(70.7)$ & \\
\hline Black & $1426(18.3)$ & $1200(17.3)$ & $99(27.2)$ & $127(26.3)$ & \\
\hline Other & $213(2.7)$ & $189(2.7)$ & $10(2.7)$ & $14(2.9)$ & \\
\hline Diabetes duration (years), mean (SD) & $1.1(0.6)$ & $1.1(0.6)$ & $1(0.6)$ & $1.2(0.5)$ & $<0.0001$ \\
\hline Baseline $\mathrm{HbA} 1 \mathrm{c}(\%)$, mean (SD) & $7.2(1.5)$ & $6.9(1.0)$ & $11.6(1.6)$ & $8.5(1.6)$ & $<0.0001$ \\
\hline Family History of CAD, $n(\%)$ & $1398(18)$ & $1235(17.8)$ & $58(15.9)$ & $105(21.8)$ & 0.05 \\
\hline Tobacco, $n(\%)$ & $4367(56.1)$ & $3889(56.1)$ & $198(54.4)$ & $280(58.1)$ & 0.55 \\
\hline Hypertension, $n(\%)$ & $7060(90.7)$ & $6296(90.8)$ & $322(88.5)$ & $442(91.7)$ & 0.25 \\
\hline Hyperlipidemia, $n(\%)$ & $6819(87.6)$ & $6093(87.9)$ & $312(85.7)$ & $414(85.9)$ & 0.23 \\
\hline BMI $\left(\mathrm{kg} / \mathrm{m}^{2}\right)$, mean (SD) & $33.1(6.2)$ & $33(6.2)$ & $32.9(6.6)$ & $33.7(6.6)$ & 0.13 \\
\hline Framingham risk score, mean (SD) & $19.7(10.9)$ & $19.8(10.9)$ & $19.4(11.3)$ & $18.7(10.7)$ & 0.03 \\
\hline $\mathrm{PAD}, n(\%)$ & $1013(13)$ & $912(13.2)$ & $49(13.5)$ & $52(10.8)$ & 0.32 \\
\hline $\mathrm{HF}, n(\%)$ & $1086(14)$ & $925(13.3)$ & $72(19.8)$ & $89(18.5)$ & $<0.0001$ \\
\hline COPD, $n(\%)$ & $1264(16.2)$ & $1149(16.6)$ & $52(14.3)$ & $63(13.1)$ & 0.08 \\
\hline $\mathrm{CKD}, n(\%)$ & $1053(13.5)$ & $927(13.4)$ & $57(15.7)$ & $69(14.3)$ & 0.40 \\
\hline Dialysis, $n(\%)$ & $112(1.4)$ & $105(1.5)$ & $4(1.1)$ & $3(0.6)$ & 0.24 \\
\hline Depression, $n(\%)$ & $2414(31)$ & $2130(30.7)$ & $115(31.6)$ & $169(35.1)$ & 0.13 \\
\hline PTSD, $n(\%)$ & $1396(17.9)$ & $1257(18.1)$ & $56(15.4)$ & $83(17.2)$ & 0.38 \\
\hline \multicolumn{5}{|l|}{ Presentation, $n(\%)$} & 0.26 \\
\hline Stable angina & $216(2.8)$ & $198(2.9)$ & $9(2.5)$ & $9(1.9)$ & \\
\hline Positive functional study & $1825(23.5)$ & $1630(23.5)$ & $79(21.7)$ & $116(24.1)$ & \\
\hline Ischemic heart disease & $522(6.7)$ & $465(6.7)$ & $30(8.2)$ & $27(5.6)$ & \\
\hline Chest pain & $5217(67.1)$ & $4641(66.9)$ & $246(67.6)$ & $330(68.5)$ & \\
\hline Acute coronary syndrome & $504(6.5)$ & $433(6.2)$ & $33(9.1)$ & $38(7.9)$ & \\
\hline \multicolumn{5}{|l|}{ Post-angiography revascularization, $n(\%)$} & 0.08 \\
\hline None & $4878(62.7)$ & $4335(62.5)$ & $225(61.8)$ & $318(66)$ & \\
\hline PCI & $1831(23.5)$ & $1634(23.6)$ & $100(27.5)$ & $97(20.1)$ & \\
\hline CABG & $1071(13.8)$ & $965(13.9)$ & $39(10.7)$ & 67 (13.9) & \\
\hline \multicolumn{5}{|l|}{ Coronary artery disease (CAD) status } & 0.09 \\
\hline No CAD & $1377(17.7)$ & $1242(17.9)$ & $55(15.1)$ & $80(16.6)$ & \\
\hline Non-obstructive CAD & $1566(20.1)$ & $1392(20.1)$ & $62(17)$ & $112(23.2)$ & \\
\hline Obstructive CAD & $4837(62.2)$ & $4300(62)$ & $247(67.9)$ & $290(60.2)$ & \\
\hline \multicolumn{5}{|l|}{$\mathrm{ACE}$ inhibitor/ARB } & $<0.0001$ \\
\hline Not prescribed & $2339(30.1)$ & $2127(30.7)$ & $103(28.3)$ & 109 (22.6) & \\
\hline Prescribed & $5441(69.9)$ & $4807(69.3)$ & $261(71.7)$ & $373(77.4)$ & \\
\hline $\mathrm{PDC}<0.8$ & $1164(21.4)$ & $985(20.5)$ & $65(24.9)$ & $114(30.6)$ & \\
\hline $\mathrm{PDC} \geq 0.8$ & $4277(78.6)$ & $3822(79.5)$ & $196(75.1)$ & $259(69.4)$ & \\
\hline \multicolumn{5}{|l|}{ Beta-blocker } & 0.02 \\
\hline Not prescribed & $1569(20.2)$ & $1423(20.5)$ & $69(19.0)$ & $77(16.0)$ & \\
\hline Prescribed & $6211(79.8)$ & $5511(79.5)$ & $295(81.0)$ & $405(84.0)$ & \\
\hline $\mathrm{PDC}<0.8$ & $1090(17.5)$ & $945(17.1)$ & $61(20.7)$ & $84(20.7)$ & \\
\hline $\mathrm{PDC} \geq 0.8$ & $5121(82.5)$ & $4566(82.9)$ & $234(79.3)$ & $321(79.3)$ & \\
\hline \multicolumn{5}{|l|}{ Statins } & 0.0001 \\
\hline Not prescribed & 967 (12.4) & 877 (12.6) & $43(11.8)$ & $47(9.8)$ & \\
\hline Prescribed & $6813(87.6)$ & 6057 (87.4) & $321(88.2)$ & $435(90.2)$ & \\
\hline $\mathrm{PDC}<0.8$ & $1567(23.0)$ & $1345(22.2)$ & $94(29.3)$ & $128(29.4)$ & \\
\hline $\mathrm{PDC} \geq 0.8$ & $5246(77.0)$ & $4712(77.8)$ & $227(70.7)$ & $307(70.6)$ & \\
\hline
\end{tabular}

Abbreviations: CAD coronary artery disease, BMI body mass index, PAD peripheral artery disease, HF heart failure, COPD chronic obstructive pulmonary disease, CKD chronic kidney disease, PTSD post-traumatic stress disorder, ACE inhibitor angiotensin-converting enzyme inhibitor, ARB angiotensin receptor blocker, Statin HMG-CoA-reductase inhibitor, HbAlc hemoglobin Alc, PDC proportion of days covered

classes $\mathrm{A}$ and $\mathrm{C}(P=0.04)$ but not between classes $\mathrm{A}$ and $\mathrm{B}(P=1.0)$ or between classes $\mathrm{B}$ and $\mathrm{C}(P=1.0)$ (Fig. 2b).

In an exploratory analysis of diabetes medication prescriptions, individuals in class A were more likely to be on no medications (Fig. 3a, Table S11) and were less likely to be prescribed insulin (Fig. 3b, Table S12) across all time points examined. Individuals in $\mathrm{HbA} 1 \mathrm{c}$ trajectory classes $\mathrm{B}$ and $\mathrm{C}$ were similar with regard to the number of diabetes medications and medication classes prescribed at baseline and across all timepoints during follow-up (Fig. 3a, b, Tables S11 and
$\mathrm{S} 12)$. Adherence to cardioprotective medications was lower in all three-trajectory classes at 12 months after cardiac catheterization than at baseline, but the relative proportions of adherence between classes $\mathrm{A}, \mathrm{B}$, and $\mathrm{C}$ were similar at baseline (Table 1) and 12 months (Table S13). Individuals in class A had higher adherence to sulfonylureas and metformin than those in classes B and $\mathrm{C}$ at 12 months after catheterization (Table S13). Sulfonylurea adherence was higher in class $C$ individuals than in class $\mathrm{B}$, while metformin adherence was higher in class B than in class C (Table S13). Crude 2-year mortality was numerically higher in individuals with lower 


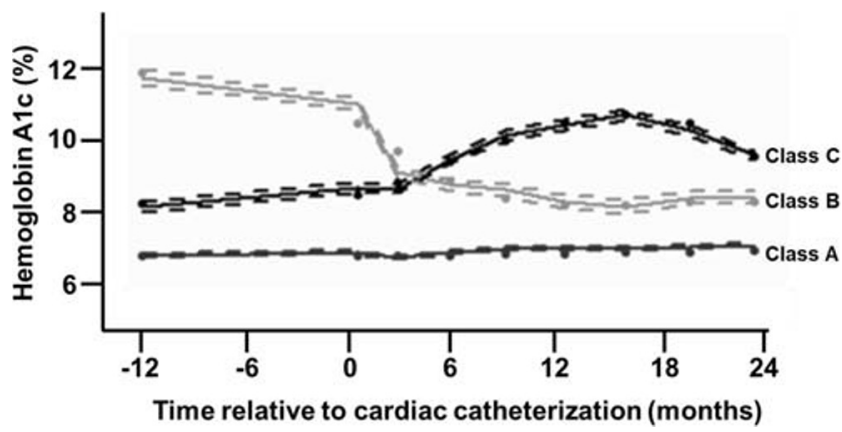

Fig. 1 Hemoglobin A1c trajectory classes in individuals with diabetes who undergo cardiac catheterization. Predicted and observed longitudinal hemoglobin A1c (HbA1c) trajectories plotted over time from a three-class joint latent class mixed model that includes the last $\mathrm{HbA1c}$ value preceding cardiac catheterization (day 0 ) and all measurements during up to two 2 years of follow-up. Predicted values for class members indicated with solid dots, observed values indicated with solid lines, and $95 \%$ confidence intervals indicated with dashed lines.

adherence to ACEi/ARB, beta-blocker, statin, and sulfonylurea, but did not differ across levels of metformin adherence
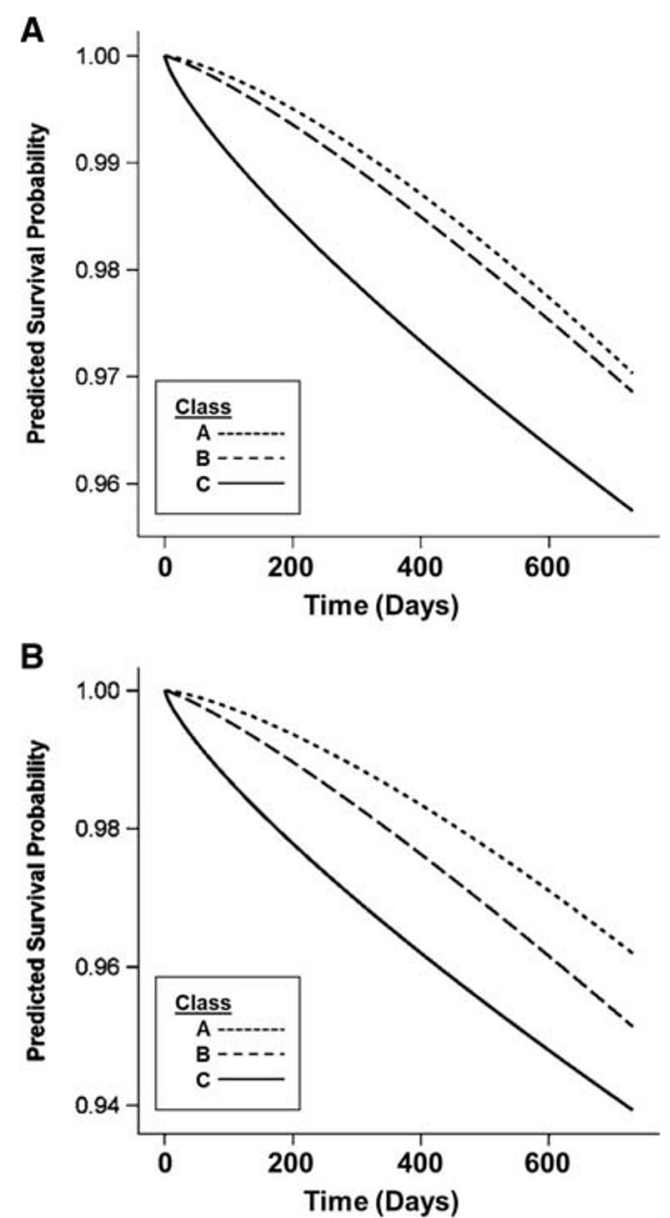

Fig. 2 Predicted survival probability over 2 years after cardiac catheterization for individuals in three hemoglobin A1c trajectory classes. Predicted survival probability based on multivariable joint latent class mixed models, adjusted for demographic and clinical covariates, in the full study cohort (a) and in those diagnosed with obstructive coronary artery disease at the time of cardiac catheterization (b).
Table 2 Association Between Baseline HbA1c and 2-Year Mortality

\begin{tabular}{lll}
\hline \hline & $\begin{array}{l}\text { Hazard ratio } \\
(\mathbf{9 5 \%} \mathbf{C I})\end{array}$ & P value $^{*}$ \\
\hline $\mathrm{HbA} 1 \mathrm{c}<7 \%(53 \mathrm{mmol} / \mathrm{mol})$ & Ref & - \\
$7 \% \leq \mathrm{HbA} 1 \mathrm{c}<9 \%(53-74 \mathrm{mmol} / \mathrm{mol})$ & $1.01(0.96,1.06)$ & 0.81 \\
$\mathrm{HbA} 1 \mathrm{c} \geq 9 \%(\geq 75 \mathrm{mmol} / \mathrm{mol})$ & $1.02(0.95,1.10)$ & 0.58 \\
\hline *Type 3 Wald test $P=0.85$ for difference across 3 baseline HbAlc groups &
\end{tabular}

(Table S13). There were too few mortality events to compare the associations of adherence with mortality between $\mathrm{HbAlc}$ trajectory classes.

\section{DISCUSSION}

In this study, we found three glycemic control trajectories in diabetes patients without and with objectively determined CAD receiving real-world clinical care. Two of the trajectory classes exhibited a qualitative inflection point at or near the

A

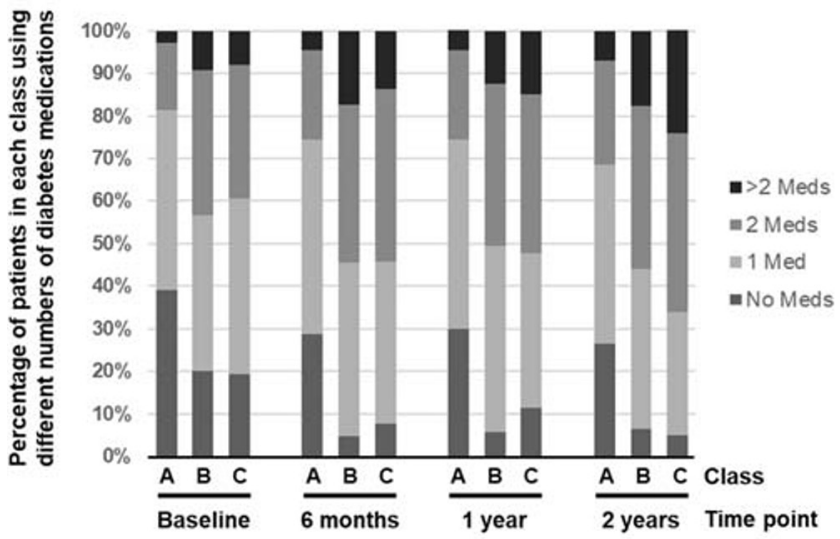

B

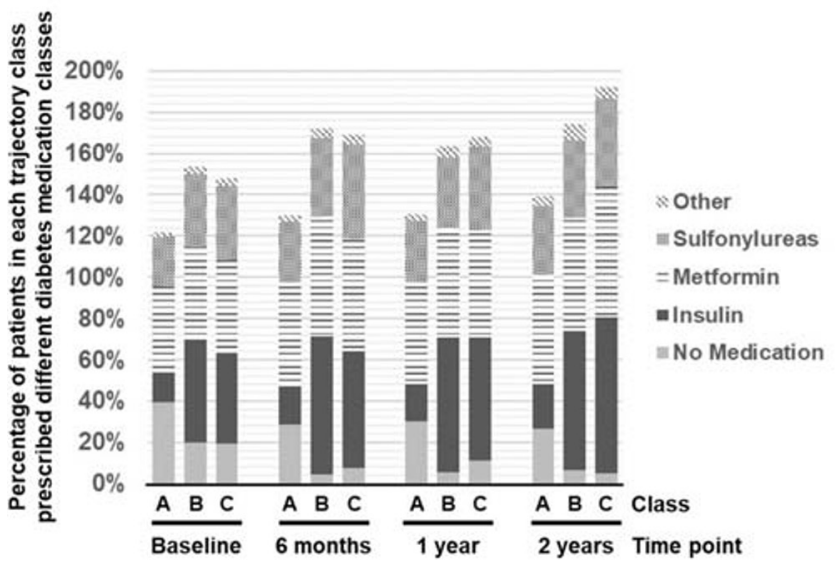

Fig. 3 Diabetes medication distribution over two years of follow-up across HbA1c trajectory classes. Proportion of participants in HbA1c trajectory Class $\mathrm{A}, \mathrm{B}$, and $\mathrm{C}$ on $\mathbf{0}, \mathbf{1}, \mathbf{2}$, or $>2$ diabetes medications at baseline, 6,12 , and 24 months after cardiac catheterization (A). Proportion of participants in each HbA1c trajectory class prescribed no diabetes medications, insulin, metformin, sulfonylurea, or other diabetes medication at baseline, 6, 12, and 24 months after cardiac catheterization (B). 
time of cardiac catheterization, suggesting the clinical event may have impacted diabetes self-management or treatment in a subset of patients in this cohort. Relative to the most common trajectory-maintaining a stable, low HbA1c after catheterization - the trajectory with intermediate baseline $\mathrm{HbA} 1 \mathrm{c}$ and gradually increasing $\mathrm{HbA} 1 \mathrm{c}$ after catheterization was associated with higher short-term mortality. In contrast, a trajectory characterized by high baseline $\mathrm{HbA} 1 \mathrm{c}$ but declining after catheterization did not have higher mortality than the low, stable $\mathrm{HbA} 1 \mathrm{c}$ trajectory. Notably, $\mathrm{HbA} 1 \mathrm{c}$ at the time of cardiac catheterization was not associated with mortality.

Our analysis suggests that glycemic control trajectories may be more informative for predicting clinical outcomes than a single $\mathrm{HbAl}$ c measurement at the time of cardiac catheterization and CAD diagnosis. We have previously shown that $\mathrm{HbA} 1 \mathrm{c}$ examined as a time-varying predictor after cardiac catheterization was associated with 2-year all-cause mortality only for $\mathrm{HbAlc}$ values $<6 \%$ relative to a reference of $6.5<$ $\mathrm{HbA} 1 \mathrm{c} \leq 7 \% .{ }^{27}$ The joint latent class modeling approach taken here complements the prior work by examining associations of time-varying patterns in $\mathrm{HbAlc}$, rather than individual values, with mortality. In other words, two individuals with the same $\mathrm{HbAlc}$ value measured several months after cardiac catheterization may have distinguishable risk of mortality when that single value is placed in the context of an HbAlc trajectory based on serial measurements.

We found relatively minor differences in descriptive characteristics, if any, between the patients in each $\mathrm{HbAlc}$ trajectory class, suggesting that $\mathrm{HbAlc}$ trajectory may not be easy to predict at the time of coronary angiography based on the variables we examined. While the mortality differences between trajectory classes were small, the association between trajectories and a clinically important outcome lends credence to this approach. In fact, most EHR systems are already able to present longitudinal $\mathrm{HbA} 1 \mathrm{c}$ measurements to clinical providers, so adding $\mathrm{HbAlc}$ trajectories to clinical dashboards used to inform diabetes care may be an easily adopted change.

Prior trajectory analyses applied to $\mathrm{HbAlc}$ in diabetes patients focused on long-term glycemic control trajectories, their predictors, and their associations with subsequent rather than contemporaneous clinical outcomes. ${ }^{22-24}$ The prior work, therefore, describes how glycemic control over the natural history of diabetes predicts future clinical outcomes ("legacy effect" of glycemia ${ }^{28,29}$ ) and identifies predictors of specific glycemic control trajectories. To further understand associations of the natural history of glycemic control in diabetes patients with clinical outcomes, joint latent class mixed models could be applied to individuals with similar baseline $\mathrm{HbAlc}$ values that diverge over time. However, our goal in this study was to describe the glycemic control trajectories observed after an important clinical event, the diagnosis of $\mathrm{CAD}$, and to evaluate whether serial $\mathrm{HbAlc}$ measurements from real-world clinical care could inform diabetes care contemporaneously. Indeed, our data suggest that serial $\mathrm{HbAlc}$ measurements occurring at or near the frequency recommended by the ADA (every 6 months) ${ }^{1,}{ }^{11}$ could be used to determine whether individuals with recently diagnosed CAD exhibit high-risk glycemic control trajectories, complementing prior work evaluating long-term $\mathrm{HbAlc}$ trajectories and individual time-varying $\mathrm{HbA} 1 \mathrm{c}$ measurements.

The exploratory analysis of diabetes treatments prescribed across $\mathrm{HbA1c}$ trajectory classes suggests that differences in medication prescribing alone are unlikely to explain the different glycemic control trajectories. Class A individuals were more likely to be on no diabetes medications and less likely to be on insulin at baseline, suggesting that differences in diabetes severity at baseline could partly explain better outcomes in this group. Despite divergent $\mathrm{HbAlc}$ trajectories, patients in classes $\mathrm{B}$ and $\mathrm{C}$ were similar in treatment at baseline and during follow-up, consistent with providers basing treatment decisions on single $\mathrm{HbAlc}$ values rather than $\mathrm{HbAlc}$ trajectories. Prior studies have described higher rates of diabetes treatment intensification after acute myocardial infarction in individuals with higher $\mathrm{HbAlc},{ }^{30,31}$ and we observed a similar increase in treatment in trajectory class $\mathrm{B}$ and $\mathrm{C}$ individuals compared to those in class A.

It is important to point out that our results suggest that $\mathrm{HbA} 1 \mathrm{c}$ trajectories may help classify diabetes patients into different short-term mortality risk categories, but do not imply a causal relationship between the trajectories and mortality. That is, the HbAlc trajectory itself may not be a useful target of a clinical intervention yet may be an indicator that other intervenable factors - e.g., medication adherence or other diabetes-related health behaviors - may need attention. Moreover, our analysis did not comprehensively evaluate variables that may be associated with both $\mathrm{HbA1c}$ trajectory and mortality, for example, socioeconomic factors such as housing and income stability. Future work is needed to better define the causes and consequences of the different trajectories observed in this study. The exploratory evaluation of medication adherence performed in this study confirms crude associations of adherence with 2-year mortality and suggests variation in adherence across trajectory classes. Recent work in a similar patient population found that $\mathrm{HbAlc}$ at the time of acute myocardial infarction was correlated with adherence to cardioprotective medications in the following year, ${ }^{32}$ providing a plausible link between the rising $\mathrm{HbA} 1 \mathrm{c}$ in class $\mathrm{C}$ individuals and higher short-term mortality. Evaluating timevarying medication adherence as a predictor of trajectory classes and as a mediator of their associations with mortality would be computationally challenging in the framework of the joint modeling approach used in this study and will be evaluated in future research.

Our study has several limitations. First, we cannot conclude causality between glycemic control trajectories and short-term mortality, nor can we infer that any patient characteristics causally determine trajectory class membership. Second, the trajectory models are inherently subjective as they depend on model fit statistics and investigator-determined criteria for model selection. Third, the use of a clinical registry limited 
to individuals who had undergone cardiac catheterization makes our study susceptible to selection bias. That is, individuals who have undergone coronary angiography may not represent the general population of diabetes patients without and with CAD. Finally, our study population is predominantly male, limiting generalizability of the results.

Our study also has several clinically relevant implications. By focusing on short-term mortality, our study evaluated an important clinical outcome in a high-risk population at a vulnerable time - patients with diabetes in the first 2 years after CAD diagnosis. We provide observational evidence that $\mathrm{HbAlc}$ trajectories may be informative for classifying risk in diabetes patients, possibly more so than the last available $\mathrm{HbA1c}$ measurement upon which most guidelines currently base diabetes management recommendations. In the current era of near-universal adoption of electronic health records and interest in the "learning healthcare system", 33 computational tools or dashboards that report biomarker or risk factor trajectories in addition to the last available measurement warrant further study to determine if they can help improve outcomes.

Acknowledgments: SR is supported by American Heart Association Award 17MCPRP33670728 and VA Career Development Award IK2CX001907-01. SAB is supported by the National Institute of Diabetes and Digestive and Kidney Diseases of the National Institutes of Health under Award Number K23DK109200. LC is supported by VA HSR\&D IIR 14-048-3. JEBR, AEB, and PMH are supported by grants from the US Department of Veterans Affairs. PMH is supported by grants from National Institutes of Health, National Heart, Lung, and Blood Institute. TMM is supported by grant funding from the NIH NCATS (1U24TR002306-01: A National Center for Digital Health Informatics Innovation). The content is solely the responsibility of the authors and does not necessarily represent the official views of the Department of Veterans Affairs or the National Institutes of Health.

Corresponding Author: Sridharan Raghavan, MD, PhD; Rocky Mountain Regional VA Medical Center Medicine Service (111), 1700 North Wheeling Street, Aurora, CO 80045, USA (e-mail: sridharan. raghavan@ucdenver.edu).

Compliance with Ethical Standards:

Conflict of Interest: PMH served on a Steering Committee for a clinical trial on medication adherence for Janssen, Inc., and is the Deputy Editor for Circulation: Cardiovascular Quality and Outcomes, but reports no conflicts of interest with this study. TMM discloses consulting for Creative Educational Concepts, Inc., employment at BJC HealthCare/Washington University School of Medicine, and honoraria payments from Brown University, Washington State Clinical Outcomes Assessment Program (COAP), Virginia Mason, University of Utah, New York Presbyterian, Westchester Medical Center, and Sentara Heart Hospital, but none represent a conflict of interest with this study. The remaining authors have no conflicts of interest relevant to the work in this study.

\section{REFERENCES}

1. American Diabetes Association. 6. Glycemic targets: standards of medical care in diabetes-2019. Diabetes care. 2019;42(Suppl 1):S61-S70.

2. Whelton PK, Carey RM, Aronow WS, Casey DE, Jr., Collins KJ, Dennison Himmelfarb C, et al. 2017 ACC/AHA/AAPA/ABC/ACPM/ AGS/APhA/ASH/ASPC/NMA/PCNA guideline for the prevention, detection, evaluation, and management of high blood pressure in adults: a report of the American College of Cardiology/American Heart Association Task Force on Clinical Practice Guidelines. J Am Coll Cardiol. 2018;71(19):e127-e248.
3. American Diabetes Association. 10. Cardiovascular disease and risk management: standards of medical care in diabetes-2019. Diabetes care. 2019;42(Suppl 1):S103-S23.

4. Currie CJ, Peters JR, Tynan A, Evans M, Heine RJ, Bracco OL, et al. Survival as a function of $\mathrm{HbA}(1 \mathrm{c})$ in people with type 2 diabetes: a retrospective cohort study. Lancet. 2010;375(9713):481-9.

5. Fox CS, Golden SH, Anderson C, Bray GA, Burke LE, de Boer IH, et al. Update on prevention of cardiovascular disease in adults with type 2 diabetes mellitus in light of recent evidence: a scientific statement from the American Heart Association and the American Diabetes Association. Diabetes care. 2015;38(9): 1777-803.

6. Huang ES, Liu JY, Moffet HH, John PM, Karter AJ. Glycemic control, complications, and death in older diabetic patients: the diabetes and aging study. Diabetes care. 2011;34(6):1329-36.

7. Khaw KT, Wareham N, Bingham $\mathbf{S}$, Luben $\mathbf{R}$, Welch A, Day $\mathbf{N}$. Association of hemoglobin Alc with cardiovascular disease and mortality in adults: the European prospective investigation into cancer in Norfolk. Annals of internal medicine. 2004;141(6):413-20.

8. Rao Kondapally Seshasai S, Kaptoge S, Thompson A, Di Angelantonio E, Gao P, Sarwar N, et al. Diabetes mellitus, fasting glucose, and risk of cause-specific death. The New England journal of medicine. 2011;364(9):829-41.

9. Selvin E, Marinopoulos S, Berkenblit G, Rami T, Brancati FL, Powe NR, et al. Meta-analysis: glycosylated hemoglobin and cardiovascular disease in diabetes mellitus. Annals of internal medicine. 2004;141(6):421-31.

10. Stratton IM, Adler AI, Neil HA, Matthews DR, Manley SE, Cull CA, et al. Association of glycaemia with macrovascular and microvascular complications of type 2 diabetes (UKPDS 35): prospective observational study. Bmj. 2000;321(7258):405-12.

11. American Diabetes Association. 4. Comprehensive medical evaluation and assessment of comorbidities: standards of medical care in diabetes2019. Diabetes care. 2019;42(Suppl 1):S34-S45.

12. Chan CY, Li R, Chan JY, Zhang $\mathbf{Q}$, Chan CP, Dong M, et al. The value of admission $\mathrm{HbA}(1 \mathrm{c})$ level in diabetic patients with acute coronary syndrome. Clin Cardiol. 2011;34(8):507-12.

13. Heller SR, Bergenstal RM, White WB, Kupfer S, Bakris GL, Cushman WC, et al. Relationship of glycated haemoglobin and reported hypoglycaemia to cardiovascular outcomes in patients with type 2 diabetes and recent acute coronary syndrome events: the EXAMINE trial. Diabetes Obes Metab. 2017;19(5):664-71.

14. Lemesle G, Bonello L, de Labriolle A, Maluenda G, Syed AI, Collins SD, et al. Prognostic value of hemoglobin AlC levels in patients with diabetes mellitus undergoing percutaneous coronary intervention with stent implantation. The American journal of cardiology. 2009;104(1):415.

15. Zheng J, Cheng J, Zhang Q, Qi C, Wang T, Xiao X. Association between glycosylated hemoglobin level and cardiovascular outcomes in diabetic patients after percutaneous coronary intervention. Medicine (Baltimore). 2016;95(19):e3696.

16. Maddox TM, Plomondon ME, Petrich M, Tsai TT, Gethoffer H, Noonan G, et al. A national clinical quality program for Veterans Affairs catheterization laboratories (from the Veterans Affairs clinical assessment, reporting, and tracking program). The American journal of cardiology. 2014;114(11):1750-7.

17. Miller DR, Safford MM, Pogach LM. Who has diabetes? Best estimates of diabetes prevalence in the Department of Veterans Affairs based on computerized patient data. Diabetes care. 2004;27 Suppl 2:B10-21.

18. Ho PM, Lambert-Kerzner A, Carey EP, Fahdi IE, Bryson CL, Melnyk SD, et al. Multifaceted intervention to improve medication adherence and secondary prevention measures after acute coronary syndrome hospital discharge: a randomized clinical trial. JAMA internal medicine. 2014;174(2):186-93.

19. Maddox TM, Stanislawski MA, Grunwald GK, Bradley SM, Ho PM, Tsai TT, et al. Nonobstructive coronary artery disease and risk of myocardial infarction. JAMA. 2014;312(17):1754-63.

20. Proust-Lima C, Sene M, Taylor JM, Jacqmin-Gadda H. Joint latent class models for longitudinal and time-to-event data: a review. Statistical methods in medical research. 2014;23(1):74-90.

21. Sun J, Herazo-Maya JD, Molyneaux PL, Maher TM, Kaminski N, Zhao H. Regularized latent class model for joint analysis of high-dimensional longitudinal biomarkers and a time-to-event outcome. Biometrics. 2019;75(1):69-77.

22. Laiteerapong N, Karter AJ, Moffet HH, Cooper JM, Gibbons RD, Liu $\boldsymbol{J Y}$, et al. Ten-year hemoglobin Alc trajectories and outcomes in type 2 
diabetes mellitus: The Diabetes \& Aging Study. J Diabetes Complications. 2017;31(1):94-100

23. Luo M, Lim WY, Tan CS, Ning Y, Chia KS, van Dam RM, et al Longitudinal trends in HbAlc and associations with comorbidity and allcause mortality in Asian patients with type 2 diabetes: a cohort study. Diabetes Res Clin Pract. 2017;133:69-77.

24. Walraven I, Mast MR, Hoekstra T, Jansen AP, van der Heijden AA, Rauh SP, et al. Distinct HbAlc trajectories in a type 2 diabetes cohort. Acta diabetologica. 2015;52(2):267-75.

25. Muthen B, Brown CH, Masyn K, Jo B, Khoo ST, Yang CC, et al. General growth mixture modeling for randomized preventive interventions. Biostatistics. 2002;3(4):459-75.

26. Muthen B, Muthen LK. Integrating person-centered and variablecentered analyses: growth mixture modeling with latent trajectory classes. Alcohol Clin Exp Res. 2000;24(6):882-91.

27. Raghavan S, Liu WG, Michael Ho P, Plomondon ME, Baron AE, Caplan $\mathrm{L}$, et al. Coronary artery disease severity modifies associations between glycemic control and both mortality and myocardial infarction. J Diabetes Complications. 2018.

28. Chalmers J, Cooper ME. UKPDS and the legacy effect. The New England journal of medicine. 2008;359(15):1618-20.

29. Laiteerapong N, Ham SA, Gao Y, Moffet HH, Liu JY, Huang ES, et al. The legacy effect in type 2 diabetes: impact of early glycemic control on future complications (The Diabetes \& Aging Study). Diabetes care. 2019;42(3):416-26.

30. Stolker JM, Spertus JA, McGuire DK, Lind M, Tang F, Jones PG, et al Relationship between glycosylated hemoglobin assessment and glucose therapy intensification in patients with diabetes hospitalized for acute myocardial infarction. Diabetes care. 2012;35(5):991-3.

31. Stolker JM, Sun D, Conaway DG, Jones PG, Masoudi FA, Peterson PN, et al. Importance of measuring glycosylated hemoglobin in patients with myocardial infarction and known diabetes mellitus. The American journal of cardiology. 2010;105(8):1090-4.

32. Adamek KE, Ramadurai D, Gunzburger E, Plomondon ME, Ho PM, Raghavan S. Association of diabetes mellitus status and glycemic control with secondary prevention medication adherence after acute myocardial infarction. J Am Heart Assoc. 2019;8(3):e011448.

33. Agency for Healthcare Research and Quality, Rockville, MD. Learning health systems. Content last reviewed November 2017. http://www.ahrq. gov/professionals/systems/learning-health-systems/index.html. 2017; Accessed May 28, 2019.

Publisher's Note Springer Nature remains neutral with regard to jurisdictional claims in published maps and institutional affiliations. 